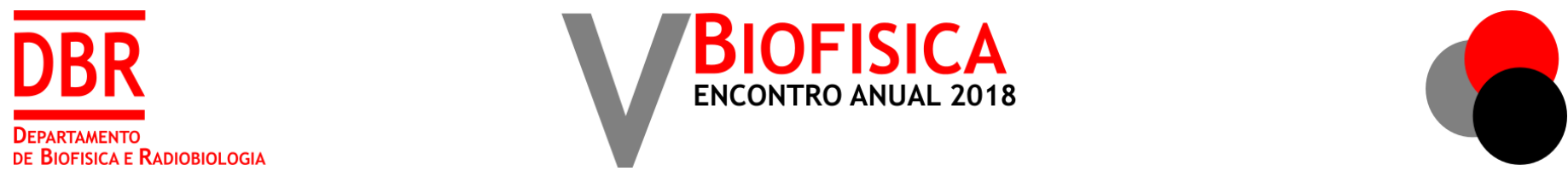

\title{
O ENSAIO DE MICRONÚCLEO EM TRADESCANTIA COMO BIOMONITOR
}

\author{
Rivaldo Rogério ${ }^{1}$, Rebeca Bandeira ${ }^{2}$, Ana Mendonça ${ }^{2}$, Mariana Brayner $^{2}$, Thiago de Salazar e Fernandes ${ }^{1}$ \\ ${ }^{1}$ Laboratório de Radiobiologia, UFPE \\ *juniorsilva160995@hotmail.com
}

\begin{abstract}
INTRODUÇÃO
O ensaio do micronúcleo em plantas do gênero Tradescantia (TRADMCN) vem sendo amplamente utilizado como teste de genotoxicidade, desde o experimento fundamental da Radiobiologia, do pesquisador Sax (1938), que mostrou que as cé lulas desta planta sofrem alterações cromossômicas quando expostas aos raios- $X$, e que na medida em que a dose de radiação aumenta, a frequência de alterações aumenta proporcional com a dose. Há diversos estudos que utilizam este tipo de planta como biomonitores ambientais para a avaliação da qualidade do ar com relação à presença de poluentes ambientais, com destaque às pesquisas desenvolvidas por um grupo de brasileiros (GUIMARÃES et al., 2000; CARVALHO-OLIVEIRA et al., 2005; FERREIRA et al., 2007; MEIRELES et al., 2009). Segundo estes pesquisadores, a Tradescantia não só permitiria avaliar a ação genotóxica de poluentes presentes no ar para a planta, como é possível correlacionar estes achados com a saúde da população, tal como a incidência de câncer naquela região (MARIANI et al., 2009). Em outro estudo, foi utilizado o teste do micronúcleo em Tradescantia, utilizando o clone 4430, resultado do cruzamento das espécies Tradescantia subacaulis e Tradescantia hirsutiflora para avaliar a possível ação genotóxica decorrente da presença de radionuclídeos naturais na região de Poços de Caldas, no entanto, nenhum aumento significativo de micronúcleos foi observado em plantas desta região (GOMES et al., 2002).
\end{abstract}

Por outro lado, há poucos relatos sobre o ensaio TRAD-MCN aplicado na investigação da possível ação genotóxica do calor, sendo este tema de grande relevância diante das perspectivas de aumento da temperatura global devido às mudanças climáticas, com possibilidade de impactar tanto a agricultura quanto a saúde humana. Há evidências que em temperaturas iguais ou superiores a $42{ }^{\circ} \mathrm{C}$, a Tradescantia já apresenta um "background" maior de micronúcleos do que comparado às plantas mantidas nas temperaturas moderadas. Além disso, a Tradescantia expressa proteínas de choque térmico (HSPs - "Heat Shock Proteins"), que sinalizam que a célula foi exposta à altas temperaturas (XIAO; MASCARENHAS, 1985). Porém, a resposta será diferente se a exposição for imediata, ou se for gradual (HALL, 2000).

A temperatura igual ou superior a $42{ }^{\circ} \mathrm{C}$, assim como as radiações ionizantes, possui uma ação clastogênica (i.e., que quebra cromossomos), levando a formação de aberrações cromossômicas instáveis (dicêntricos, anéis e fragmentos acêntricos) e micronú cleos em células expostas (HALL, 2000; RIBEIRO et al., 2003). 0 teste do micronúcleo é considerado o "padrão-ouro" de avaliação da ação genotóxica de agentes físicos e químicos (RIBEIRO et al., 2003). Os micronúcleos são um subproduto das aberrações cromossômicas instáveis ou de perdas de cromossomos inteiros. Eles consistem numa pequena massa nuclear revestida por membrana e separada do núcleo principal da célula, sendo de fácil identificação quando comparada às aberrações cromossômicas instáveis (HALL, 2006; IAEA, 2011).

A principal causa de sua formação é a produção de radicais livres. Este processo leva à oxidação nos sistemas biológicos, pois estes radicais têm um elétron livre para se ligar a qualquer outro átomo, e por isso, são extremamente reativos. Quando o material oxidado é o conteúdo do núcleo da célula (i.e., DNA e proteínas), logo surgem alterações cromossômicas estruturais (e.g., cromossomos dicêntricos) e consequentemente, os micronúcleos. Estas alteraçõ es são ditas "instáveis", pois possuem $50 \%$ de chance de vir a serem herdadas (FERNANDES et al., 2008; IAEA, 2011). Uma vez que o calor aumenta a oxigenação de muitos tecidos, outra ação decorrente da exposição às altas temperaturas é a formação de mais espécies reativas do oxigênio (ROS) devido à reação entre o oxigênio molecular com os radicais livres, causando assim mais danos cromossômicos e mais morte celular por apoptose (HALL, 2000).

Diante disso, a presente proposta de pesquisa visa melhor compreender como a planta Tradescantia pallida responde à ação do calor (hipertermia), tanto de forma aguda quanto gradual, no intuito de investigar a indução de micronúcleos pelo calor e o possí vel surgimento da termotolerância.

\section{METODOLOGIA}

Foi realizada uma revisão da literatura, com base nas seguintes palavras-chave em um sistema de busca: tradescantia e micronuclei. Nesta busca, foram encontrados 134 artigos nos quais foram selecionados os que tinham mais relevância com os temas: Poluição, genotoxicidade e radiação ionizante para o desenvolvimento deste resumo.

Foi selecionado o artigo de Guimarães et al. (2000) como base para a revisão dos efeitos de poluentes para a saúde humana, em que mudas de Tradescantia pallida cv. purpurea foram implantadas em dois locais da cidade de São Paulo, considerados com altos índices de poluição do ar. Também foi selecionada a área rural, para comparação dos resultados. As áreas escolhidas para o monitoramento ambiental nos locais com elevado nível de poluição possuem elevado tráfego de carros, ônibus e caminhões.

Outro trabalho "chave" para o Desenvolvimento desta Revisão foi o desenvolvido por Carvalho (2005), que utilizou o ensaio de micronú cleos em clone de Tradescantia, o 4430, resultado do cruzamento das espécies Tradescantia subacaulis e Tradescantia hirsutiflora para o biomonitoramento de ambiente hospitalar que emprega as radiações ionizantes para fins diagnósticos ou terapêuticos.

Para descrição da metodologia do ensaio de micronúcleos em Tradescantia, foi tomado por referência a estabelecida por Ma (1981), que descreve como realizar a seleção, fixação e conservaçã 
o das inflorescências e as etapas para a preparação das lâminas para análise citogenética, que foram esquematicamente apresentadas por Misík et. al. (2011) (Figura 1).

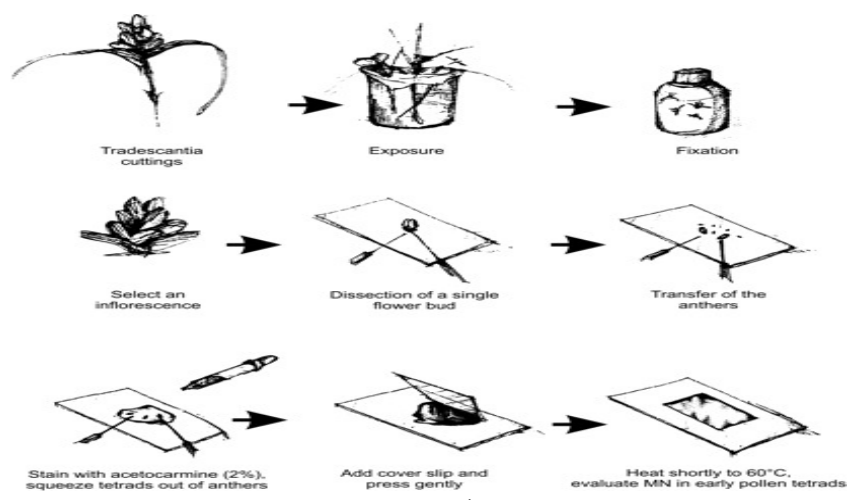

Figura 1. Diferentes etapas da preparação das lâminas (Fonte: Misik, et. al 2011).

\section{DESENVOLVIMENTO}

No trabalho de Guimarães et al. (2004), foi verificado que o ensaio de micronúcleos em Tradescantia, clone KU-20, permite avaliar o dano ambiental provocado por poluentes atmosféricos, decorrentes do trânsito da grande cidade de São Paulo. Além disso, é possível correlacionar o risco de doenças cardiovasculares com a frequência de micronúcleos elevada em Tradescantia clone KU-20, uma vez que nestas áreas mais poluídas há maior incidência de casos desta doença. Isto se deve também ao fato de que as células (gametas) de Tradescantia clone 4430, obtido após czuzamento da $T$. hirsutiflora e $T$. subacaulis e o clone 03 da Tradescantia paludosa (Figura 2) possuem uma boa correlação com células humanas (linfó citos) no que diz respeito à produção de micronúcleos por agentes genotóxicos, tal como as radiações ionizantes. Essas células podem refletir o que possivelmente acontece em células humanas por serem muito semelhantes entre si. Algumas anomalias podem ser encontradas após a exposição a esses agentes mutagênicos, como a fragmentação ou cariorréxis, que consiste na fragmentação do nú cleo picnótico, a picnose, em que vai ocorrer a condensação da cromatina no núcleo de uma célula, a perda de núcleo e o próprio micronúcleo.

Em um trabalho desenvolvido por Guimarães et. al. (2000), com plantas implantadas no local onde o trânsito de caminhões e ônibus é intenso, foi identificado um índice alto de micronúcleos nas té trades de Tradescantia pallida $\mathrm{cv}$. purpurea em relação às que estavam na área rural. A área urbana foi fortemente contaminada com poluentes, que explica a incidência de mutagêneses nestas plantas.

No trabalho de Carvalho (2005), foi discutido o ensaio de micronú cleo em Tradescantia com o clone 4430, em ambiente hospitalar que faz uso das radiações ionizantes para fins diagnósticos e terapê uticos. Segundo a autora, o teste permite verificar o grau de exposição ambiental, sendo, portanto, um biomonitor ambiental também para ambientes de trabalho que oferecem risco genotó xico. Ainda no trabalho de Carvalho (2005), foi identificado que durante a exposição aos raios- $X$, a frequência de micronúcleos também é aumentada. Segundo a autora, as inúmeras semelhanças entre a constituição genética das plantas superiores e dos mamí feros permite extrapolar esses achados para o potencial risco genotóxico para os profissionais nestes ambientes de trabalho, permitindo, assim, a maior percepção dos riscos e a observância quanto às normas de radioproteção.

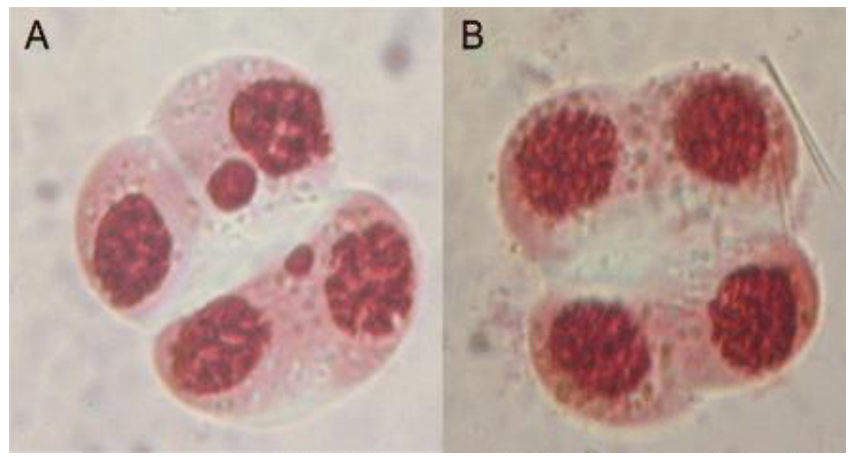

Figura 2. Tetrads de pólen precoce de Tradescantia com (a) e sem MN (b). (Fonte: Misik, et. al 2011).

\section{CONCLUSÕES}

0 atual trabalho de revisão apresenta situações reais em que o ensaio de micronúcleo em clone 4430, cruzamento das espécies Tradescantia subacaulis e Tradescantia hirsutiflora, Tradescantia pallida, Tradescantia paludosa, clone 03, e o clone KU-20 do mesmo gênero pode ser útil na avalição dos riscos à saúde humana e ao meio ambiente. O teste permite identificar os efeitos de poluentes atmosféricos, a exemplo da poluição urbana, bem como os riscos associados à saúde, além de permitir o biomonitoramento em ambientes hospitalares que fazem emprego das radiações ionizantes para fins diagnósticos e terapêuticos.

\section{REFERÊNCIAS}

CARVALHO, A. H. A Tradescantia como bioindicador vegetal na monitoração dos efeitos clastogêncicos das radiações ionizantes. Radil Bras, v. 33, n. 6, p. 459-462, 2005.

FERNANDES, T. S.; LLOYD, D.; AMARAL, A. Biodosimetry for dose assessment of partial-body exposures: a methodological improvement. Brazilian Archives of Biology and Technology, v. 51, special number, p. 97-102, 2008.

FERREIRA, M. I.; DOMINGOS, M.; GOMES, H. A.; SALDIVA, P. H. N.; ASSUNÇÃO, J. V. Evaluation of mutagenic potential of contaminated atmosphere at Ibirapuera Park, São Paulo - SP, Brazil, using the Tradescantia stamen-hair assay. Environmental Pollution, v. 145, p. 219-224, 2007.

GOMES, H. A.; NOUAILHETAS, Y.; SILVA, N. C.; MEZRAHI, A.; ALMEIDA, C. E. B.; RODRIGUES, G. S. Biological Response of Tradescantia Stamen-Hairs to High Levels of Natural Radiation in the Poços de Caldas Plateau. Brazilian Archives of Biology and Technology, v. 45, n. 3, p. 301-307, 2002.

GUIMARÃES, E. T.; DOMINGOS, M.; ALVES, E. S.; CALDINI Jr, N.; LOBO, D. J. A.; LICHTENFElS, A. J. F. C.; SALDIVA, P. H. N. Detection of the genotoxicity of air pollutants in and around the city of São Paulo (Brazil) with the Tradescantia-micronucleus (Trad-MCN) assay. Environmental and Experimental Botany, v. 44, p. 1-8, 2000.

Guimarães, E. T.; Macchione, M.; Lobo, A. J. D.; Domingos, M.; Sadiva, N. H. P. Evaluation of the Mutagenic Potential of Urban Air Pollution in São Paulo, Southeastern Brazil, Using the Tradescantia Stamen-Hair Assay. Environmental Toxicology, v. 19, n. 6, p. 578584, 2004.

HALL, E. J. Radiobiology for the Radiologist. 5. ed. Philadelphia: Ed. Lippincott Company, 2000. 558 p.

HALL, E. J.; GIACCIA, A. J. Radiobiology for the Radiologist. 6. ed. Philadelphia: Ed. Lippincott Williams \& Wilkins, 2006. 546 p. INTERNATIONAL ATOMIC ENERGY AGENCY (IAEA). Cytogenetic analysis for radiation dose assessment. Technical report series. 2011. 
MA, T. H. Tradescantia micronucleus bioassay and pollen tube chromatid aberration test for in situ monitoring and mutagen screening. Environmental Health Perspectives, Estados Unidos, v. 37, p. 85-90, 1981.

MARIANI, R. L.; JORGE, M. P. M.; PEREIRA, S. S.; MELIONE, L. P.; CARVALHO-OLIVEIRA, R.; MA, T. H.; SALDIVA, P. H. N. Association between micronuclei frequency in pollen mother cells of Tradescantia and mortality due to cancer and cardiovascular diseases: a preliminary study in São José dos Campos, Brazil. Environmental Pollution, v. 157, p. 1767-1770, 2009.

MEIRELES, J.; ROCHA, R.; NETO, A. C.; CERQUEIRA, E. Genotoxic effects of vehicle traffic pollution as evaluated by micronuclei test in tradescantia (Trad-MCN). Mutation Research, v. 675, p. 46-50, 2009.

MISÍK, M.; MA, T-H.; NERSESYAN, A.; MONARCA, S.; KIM, J. K.; KNASMUELLER, M. Micronucleus assays with Tradescantia pollen tetrads: an update. Mutagenesis, v. 26, n. 1, p. 215-221, 2011.

RIBEIRO, Lucia Regina; SALVADORI, Daisy Maria Fávero; MARQUES, Edmundo Kanan. Mutagênese Ambiental. 1. ed. Canoas: Ed. ULBRA, 2003. 355p.

SAX, K. Chromosome aberrations induced by X-rays. Genetics, v. 23, p. 494-516, 1938.

XIAO, C. M.; MASCARENHAS, J. P. High temperature-induced thermotolerance in Pollen Tubes of Tradescantia and Heat-Shock Proteins. Plant Physiology, v. 78, p. 887-890, 1985. 